\title{
Retratos da dança japonesa em Londrina, Paraná
}

\author{
Vitor Hugo Marani' \\ Fernanda Marques Tresinari Camargo \\ Silvia Pavesi Sborquia ${ }^{3}$
}

\section{RESUMO}

Esta pesquisa buscou investigar as manifestações da dança japonesa em Londrina, no Paraná, por meio da apreensão dessa cultura corporal via diálogo com diferentes grupos que se organizam na cidade. Para tanto, utilizou como procedimento de coleta de dados a análise documental - constituída por reportagens da dança japonesa no Jornal Folha de Londrina de 1980 a 2010 - e entrevistas semiestruturadas com coordenadores dos grupos mapeados. O tratamento dos dados seguiu a análise de conteúdo temática, baseada nas transcrições dos relatos. A inferência dos dados permitiu concluir que a dança japonesa na cidade de Londrina, no Paraná, estrutura-se no sentido de contribuir com a permanência da cultura dos japoneses imigrantes e suas famílias, e, também para construir uma cultura própria da colônia que se estabeleceu na região, adaptada a partir das novas demandas culturais remanescentes da sociedade contemporânea.

Palavras-chave: Cultura corporal. Manifestações populares. Dança.

1 Doutorando Educação Física. Docente do Departamento de Educação Física da Universidade Federal de Mato Grosso/Campus Universitário do Araguaia (UFMT/CUA). Barra do Garças/Mato Grosso, Brasil.

E-mail: vitorhmarani@gmail.com

2 Graduada em Educação Física junto à Universidade Estadual de Londrina (UEL). Londrina/Paraná, Brasil. E-mail: fernandatresinari@hotmail.com

3 Doutora em Educação Física pela. Docente do Departamento de Educação Física, Centro de Educação Física e Esportes, Universidade Estadual de Londrina (UEL). Londrina/Paraná, Brasil. E-mail: silviapavesi@uel.br

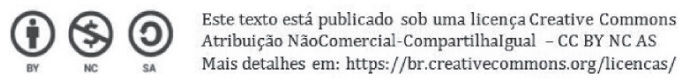




\title{
Portraits of japanese dance in Londrina, Paraná
}

\begin{abstract}
This research sought to investigate the manifestations of Japanese dance in Londrina, Paraná, through the apprehension of this body culture through dialogue with different groups that are organized in the city. To do so, it used as a data collection procedure the documentary analysis - constituted by Japanese dance reports in the Folha de Londrina newspaper from 1980 to 2010 - and semi-structured interviews with coordinators of the mapped groups. The treatment of the data followed the analysis of thematic content, based on the transcriptions of the reports. The inference of the data allowed to conclude that the Japanese dance in the city of Londrina, in the state of Paraná, is structured in order to contribute to the permanence of the culture of Japanese immigrants and their families, and also to construct a culture of the colony that established itself Here adapted from the new cultural demands of contemporary society.
\end{abstract}

Keywords: Body culture. Popular manifestations. Dance.

\section{Retratos de la danza japonesa en Londrina, Paraná}

\section{RESUMEN}

Esta investigación buscó investigar las manifestaciones de la danza japonesa en Londrina, en el Paraná, por medio de la aprehensión de esa cultura corporal vía diálogo con diferentes grupos que se organizan en la ciudad. Para ello, utilizó como procedimiento de recolección de datos el análisis documental - constituido por reportajes de la danza japonesa en el Jornal Folha de Londrina de 1980 a 2010 - y entrevistas semiestructuradas con coordinadores de los grupos mapeados. El tratamiento de los datos siguió el análisis de contenido temático, basado en las transcripciones de los relatos. La inferencia de los datos permitió concluir que la danza japonesa en la ciudad de Londrina, en el Paraná, se estructura en el sentido de contribuir a la permanencia de la cultura de los japoneses inmigrantes y sus familias, y también para construir una cultura propia de la colonia que se estableció Por aquí, adaptada a partir de las nuevas demandas culturales remanentes de la sociedad contemporánea.

Palabras clave: Cultura corporal. Manifestaciones populares. Danza. 


\section{INTRODUÇÃO}

A dança, embora compreendida como manifestação corporal presente em diferentes tempos e espaços, notoriamente recebeu olhares focalizados no bojo das relações sociais estabelecidas no ocidente, especificamente, nos territórios em que a industrialização apresentou maiores avanços na modernidade, a exemplo dos países da Europa e dos Estados Unidos. Essa perspectiva pode ser evidenciada em estudos ${ }^{4}$ que, comumente, trazem os aspectos histórico-sociais da dança restritos apenas a uma racionalidade, o que marginaliza conhecimentos produzidos em outras localidades culturais.

Desse panorama, aponta-se a necessidade de tematização da dança e de seus elementos constitutivos a partir de outras técnicas corporais ${ }^{5}$, entendendo que o fomento de reflexões advindas de diferentes contextos pode contribuir para o aprimoramento epistemológico da referida manifestação, como sugere Lara (2013a). Parte-se do pressuposto que a dança, inserida na cultura corporal de movimento, integra conjunto de saberes de todas as manifestações humanas nas quais o movimento transporta e conduz significados culturais, produzido e reproduzido conforme o contexto, crenças, valores e características de cada grupo social, portanto, um artefato cultural produzido pela gestualidade sistematizada (NEIRA; NUNES, 2006).

Propõe-se, nesse cenário, o alargamento do universo humano através do diálogo com o outro ${ }^{6}$, trazendo à tona sua descrição de maneira inteligível e comprometida com a alteridade, como sugere Geertz (1989). Visualiza-se, como faz Sborquia e Neira (2008), a linguagem corporal como constituidora das formações internalizadas pela infinidade de gestos significantes que estão em constante diálogo com o ambiente cultural. Por isso, a necessidade de discussão e aprimoramento do campo gestual junto ao debate acadêmico e social, com o intuito de atribuir voz àqueles que, muitas vezes não aparecem no cenário, mas que podem contribuir para o entendimento da dança em diferentes contextos étnicos.

Emerge desse contexto, a visualização do "outro", materializado pelo estudo da dança japonesa num contexto brasileiro, qual seja, o da cidade de Londrina, por meio de grupos de dança que compõem a cena local. Tal visualização foi edificada a partir da percepção de que Londrina é um espaço com um processo de colonização e de presença de japoneses e descendentes bastante marcantes, tornando-se um local a ser analisado. Considera-se que essa etnia busca a sua distinção dentro da sociedade brasileira, definindo suas fronteiras identitárias e enquadrando sua memória, uma vez que possui prevalência de imigrantes japoneses, cujos símbolos culturais têm influenciado hábitos e costumes locais (MAESIMA, 2012).

4 Entre os estudos que investigam os aspectos históricos da dança estão os escritos de Boucier (2001), Faro (1998) e Portinari (1989).

5 O termo faz menção aos escritos de Mauss (1974), ao compreender as técnicas corporais como parte da cultura que são passadas de geração para geração por meio da tradição de um dado povo.

6 Segundo Silva (2000, p. 97), o outro é "o outro gênero, o outro é a cor diferente, o outro é a outra sexualidade, o outro é a outra raça, o outro é a outra nacionalidade, o outro é o corpo diferente". 
Por tal razão, a compreensão sobre as manifestações da dança japonesa tem como ponto de partida a discussão local para a discussão global, retornando ao local com o conhecimento construído de maneira ampliada, elucidando como os significados são produzidos e (re)significados por diversos grupos. Santos (2003) argumenta que todo o conhecimento é local e total, constituído em meio a temas que, em dado momento, são adotados por grupos sociais concretos como projetos de vida locais e, posteriormente, podem ser utilizados fora do seu contexto de origem.

Buscou-se, nesse trabalho, uma compreensão desses grupos de brasileiros que, de maneira ou outra, preservam as tradições culturais japonesas, procurando interpretar os seus signos no contexto das ações expressas junto às diferentes danças encontradas. Assim, o objetivo geral do estudo estruturou-se a partir da investigação das manifestações da dança japonesa em Londrina, no Paraná, por meio da apreensão dessa cultura corporal via diálogo com diferentes grupos que se organizam com o intuito de assimilar, transmitir e, quando necessário, transgredir a tradição quando novas demandas surgem nos diferentes contextos em que se inserem.

\section{METODOLOGIA}

O presente artigo estrutura-se como resultado de projeto de investigação institucional que se preocupou com a compreensão dos significados culturais da dança na cidade de Londrina, aprovado pelo Comitê de Ética por meio do Parecer n. ${ }^{\circ}$ 01888712.5.0000.5231. No primeiro momento, a pesquisa focou no mapeamento dos grupos de dança organizados em Londrina por meio do levantamento documental de matérias que faziam referência à dança, publicadas no Jornal Folha de Londrina no período de 1980 e 2010. O procedimento de coleta de dados foi realizado por meio de fotografias e digitalização das imagens a partir da coleta junto ao acervo de 10.800 edições do Jornal Folha de Londrina disponível no Centro de Documentação e Pesquisa Histórica da Universidade Estadual de Londrina.

A pesquisa identificou quinze reportagens que apresentavam a existência de grupos de dança japonesa em Londrina e tomou como orientações investigativas a Análise de Conteúdo (BARDIN, 2011), tendo como categorias a priori: a) divulgação da dança no jornal Folha de Londrina; b) grupos existentes; c) aspectos culturais das danças dos grupos identificados. De modo geral, essa etapa da pesquisa possibilitou a identificação de uma grande diversidade de grupos de dança na cidade que se configuravam a partir da disseminação do balé clássico, da dança flamenca, da dança de rua, da dança de salão, da dança árabe, da dança japonesa e da dança afro-brasileira (CAMARGO; SBORQUIA, 2013).

Dentre a diversidade de grupos, o recorte eleito para esse texto dá-se pela apreensão da dança japonesa como foco investigativo. O tratamento isolado de cada manifestação cultural não ocorreu via juízo valorativo, pelo contrário, estabeleceu-se no sentido de valorizar as peculiaridades evidenciadas em cada modo de dançar e de expressão dos grupos encontrados junto à investigação. Nesse sentido, a análise dos jornais permitiu a identificação de três grupos de dança japonesa, sendo eles: 1) Grupo Hikari, existente 
desde 2006; 2) Grupo Sansey, existente desde 1988; e, 3) Grupo RyukyuKoku Matsuri Daiko, existente desde 1982.

No segundo momento da pesquisa, optou-se pelo procedimento de coleta de dados a partir de entrevista semiestruturada com os coordenadores dos Grupos de Dança ${ }^{7}$ (TRIVIÑOS, 1997). A entrevista seguiu os procedimentos da análise de conteúdo temática, sendo estabelecidas categorias que buscavam entender a tradição do grupo; a transmissão cultural da dança; e, os sentidos e significados da dança. O tratamento dos dados coletados seguiu um processo de interpretação, o qual implicou no constante movimento entre as partes e o todo, a partir de leituras que visassem a categorização dos dados obtidos por meio das entrevistas realizadas.

Tem-se, no presente estudo, a apresentação de subsídios para entender a etnia japonesa presente no Brasil, embora focalizada num contexto localizado, com o intuito de perceber como o campo gestual se afirma e, ao mesmo tempo, se desloca a partir de processos de hibridização cultural em meio à sociedade globalizada. Com isso, tem-se a intenção de atentar-se a práticas que pouco são visíveis nos meios de comunicação e que, comumente, são retratadas apenas em datas comemorativas, mas que apresentam noções sobre dança e movimento que podem orientar outros campos de conhecimento relacionados a essas temáticas.

\section{Aspectos histórico-culturais da dança japonesa no Brasil}

A imigração japonesa, bem como a de outras nacionalidades, ocorreu intensamente. No Brasil tal processo ocorreu no início do século XX, como explica Sano (1989). O autor faz algumas ressalvas sobre a saída dos emigrantes japoneses de seu país de origem, a exemplo do aspecto ilusório, ou não, relacionado ao "paraíso brasileiro", uma vez que os japoneses emigraram porque não tinham meios de permanecer em seu país de origem. A transição da era feudal para a capitalista trouxe reflexos dolorosos para a comunidade rural daquele país. Oguido (1988) ressalta que foram razões de ordem socioeconômicas que passaram a exigir que o Japão promovesse a emigração de seu povo.

O Brasil, após a abolição da escravatura, em 1888, apresentou defasagem na mão de obra para a colheita do café. E os japoneses, assim como os italianos, alemães, belgas, e tantos outros, foram incluídos nos contingentes de trabalhadores rurais. Fernandes (2010) mostra que a discussão sobre a entrada de asiáticos no Brasil começou a ser debatida durante o reinado de D. Pedro II, como tentativa de solução para o problema da falta de mão de obra, devido à extinção do tráfico de escravos trazidos da África. Porém, o governo mostrou-se contrário a um estreitamento nas relações diplomáticas com países asiáticos.

Os japoneses tiveram que vencer barreiras como a opinião pública e a governamental que se manifestavam contrárias aos asiáticos e favoráveis a imigração europeia. Tal

7 As entrevistas foram realizadas presencialmente com os coordenadores de cada grupo de dança e foram gravadas em aparelho eletrônico. Após, foram transcritas e, para fins sigilosos, cada coordenador recebeu a codificação a partir da letra " $\mathrm{C}$ " sequencialmente numeradas (C1, C2 e C3). 
fato é constatado pela visualização de políticas imigratórias que objetivavam promover, no século XIX, a entrada de imigrantes "desejáveis", que viriam a "embranquecer" o Brasil, baseados na proposição eugênica de que uma "raça nacional" única era biologicamente possível, o que excluía a vinda dos asiáticos para o Brasil.

No início do século XX, houve a intenção de se examinar a possibilidade em receber grupos étnicos não-europeus. Após quinze anos de negociação, as questões burocráticas foram resolvidas e, entre 1908 e 1941, ingressaram no país cerca de 189 mil imigrantes japoneses, quase todos contando com alguma espécie de subsídio. Como sugere Alvim (1998) a convivência de europeus, africanos e asiáticos portadores de culturas e hábitos tão dispares, passaram a conviver entre si, o que deu início ao processo de hibridização cultural.

A região Norte do Paraná, nas décadas de 1930 e 1950, encontrava-se num período de movimento de expansão demográfica e econômica sobre as terras até então ocupadas por indígenas e/ou caboclos. A chegada dos imigrantes japoneses ao município de Londrina ocorreu a partir da década de 1930 e, desde a década de 1940, a região Norte do Paraná, onde Londrina se insere, é tida como a segunda maior concentração de japoneses no Brasil (ARIAS NETO, 1998; FERNANDES, 2010; SCHWARTZ, 2005).

A presença de imigrantes japoneses e descendentes nessa região ocorreu devido à ação da Companhia de Terras Norte do Paraná (CTNP), uma empresa privada de origem inglesa que realizou a venda de inúmeros lotes rurais na região Norte do Paraná, entre as décadas de 1930 e 1940. O trabalho de Arias Neto (1998) acerca das representações da política em Londrina, destaca dois momentos distintos no processo de ocupação da região. O primeiro deles é identificado com a ideia de Terra da Promissão, em que o autor analisa as representações do empreendimento imobiliário inglês junto ao norte do Paraná, em fins das décadas de 1920 e 1930, e, o segundo, com o Eldorado Cafeeiro, outra representação da cidade e região, construída durante os anos de 1940, motivada pelo grande desenvolvimento da cafeicultura.

Por meio dessa ação, os japoneses tiveram a oportunidade de sair da situação de empregados nas fazendas de café paulistas e de se tornarem proprietários. Os japoneses e descendentes na referida região do país tiveram de se relacionar de forma mais aprofundada com os outros imigrantes de outros países e os nacionais. Fernandes (2010) analisa o processo de inserção desse grupo étnico nas sociedades envolventes e o processo de construção de identidades das gerações de imigrantes que viveram no meio rural entre 1830 e 1930 e de seus descendentes que foram viver no meio urbano, principalmente entre as décadas de 1950 e 1970. Os japoneses organizaram-se em núcleos coloniais com o intuito de cooperação mútua entre os membros e a educação dos filhos. Segundo Wawzyniak (2008, p. 185) os valores culturais presentes nas formações dessas colônias proporcionaram "a construção de uma etnicidade fundada no pertencimento e na reciprocidade, crescendo a função de aproximar os japoneses pela mentalidade".

As colônias variavam entre elas dependendo da origem, religião ou crença, entre outros elementos identitários. Esse processo resultava em uma grande diversidade e complexidade na organização social e cultural, alicerçada pela tradição e regras. A partir da década de 1930, a colônia propiciou a formação de uma rede de solidariedade entre os 
japoneses, permitindo a sobrevivência nas zonas rural e urbana, tornando-se uma possibilidade de estreitamento e vínculos entre eles, principalmente após a Segunda Guerra, passando a desempenhar um importante papel na organização da vida dos imigrantes e seus descendentes. As colônias constituíram-se como campo de relações e comunicação, preservando uma identificação étnica e valorizando traços culturais que refletiam a sua organização social (YAMAKI, 2008).

Nessas colônias, eram organizadas escolas $^{8}$ com objetivo de uma formação educacional com base em uma matriz japonesa, para preparar os filhos para o momento do retorno à terra natal. A escola tinha um papel fundamental na sobrevivência das identidades do grupo étnico, como preservação da diferença mediante o processo educacional. Tal estratégia, possibilitou a manutenção de uma representação da sociedade japonesa em um território estrangeiro. Nas primeiras décadas de colonização, identificou-se a colônia e a escola como elementos fundamentais de sobrevivência. Esses elementos podem servir como referências para elucidar as práticas corporais dançantes praticadas por este grupo étnico. Fernandes (2010) afirma que além da educação, a parte de esportes era uma preocupação dos japoneses como uma maneira de manter a cultura e costumes japoneses.

As relações de sociabilidade intraétnica e etnicidade nipo-brasileira eram vigorosamente perceptíveis no associativismo e na organização das atividades culturais dos japoneses em Londrina (MAESIMA, 2012), como por exemplo: os bailes de carnaval na ACEL (Associação Cultural e Esportiva de Londrina); os bailes na ACROL (Associação Cultural e Recreativa Okinawa de Londrina); as festas do Bom Odori (danças japonesas) que ocorriam no templo budista Oterá; eventos culturais e esportivos proporcionados pelas várias escolas japonesas, clubes e entidades religiosas da cidade. Destaca-se, também, assistência social, promoções de festas, atividades artísticas (dança, teatro) e excursões (ASARI, 1992). Decorre daí a verificação dos primeiros registros sobre a presença das práticas corporais da dança que começam a ser praticadas em Londrina.

\section{Retratos da dança japonesa em Londrina}

Os retratos da dança japonesa a serem expostos no artigo tematizam o campo gestual que assinala formas próprias de agir, pensar e sentir de dado grupo social e que são expressas nas práticas corporais de diferentes culturas. $\mathrm{O}$ anseio em conhecer tais manifestações, embora focalizada numa discussão local - via diálogo estabelecido com os grupos nipônicos da cidade de Londrina, no Paraná - atenta-se à compreensão global da cultura, entendendo-a como campo de lutas que se dinamiza a partir das mesclas simbólicas

8 Segundo Capelo (2000), a primeira escola japonesa de Londrina começou a funcionar em 1933, na área urbana do município, onde também funcionava o clube japonês. Entre os anos de 1946 e 1961, funcionou outra escola japonesa na região, que chegou a atingir 350 alunos e, que contava com campo de esportes, teatro e música. Na década de 1960, havia 11 escolas japonesas na cidade. Devido a iminência da Segunda Guerra Mundial, as escolas japonesas passaram para o governo local. Após o conflito, o objetivo da escolarização permaneceu relacionado à transmissão da língua e cultura, não se tratando mais de escolas exclusivas para japoneses. 
e materiais, entre o entendimento do popular, do midiático e do elitista, demarcados pelas transformações decorrentes da sociedade contemporânea (CANCLINI, 2004).

\section{Da dança no Grupo Hikari}

O Grupo Hikari, criado em 2006, é uma entidade informal construída por ex-integrantes de jovens (seinenkai) da Igreja Budista Nishi Honganji, de Londrina. Institui-se como entidade sem fins lucrativos que tem como objetivos a promoção de eventos com a finalidade de arrecadar fundos e prestação de serviços destinando-os a entidades assistenciais; o estímulo ao trabalho em equipe fortalecendo amizade e a qualidade de vida dos integrantes; e, o resgate e manutenção da dança do Bon Odori na comunidade nipo-brasileira.

No Japão, a celebração do Bom Odori ocorre no mês de agosto, momento em que acreditam que os ancestrais visitam os vivos, o que faz com que os japoneses instalem lanternas para guiar as almas na ida e na volta de suas casas, oferecendo comida aos mortos (OGAMA, 2002). No contexto festivo, a dança se insere como homenagem aos antepassados e é cultivada em ritos religiosos e executada pelos nikkeis como forma de preservação da cultura do povo do sol nascente. São os próprios dançarinos de Bon Odori que possuem o conhecimento musical e elaboram as coreografias apresentadas no evento, sendo a maioria dos participantes com idade superior aos 60 anos (KUBOTA, 2008).

No Brasil, especialmente no contexto da cidade de Londrina, o Bon Odori seria, portanto, uma tentativa de elo da colônia japonesa no Brasil com os costumes japoneses, mesmo que realizado de uma forma diferente do original. Percebeu-se que essa ligação é feita no momento em que elementos da cultura japonesa, tais como músicas, danças, comidas e decorações, são incorporados aos ensaios e apresentações das danças organizadas pelo grupo com o intuito de representar a cultura japonesa manifestada por seus descendentes. A dança é apresentada em festas e comemorações, principalmente no Odori Fest, que ocorre anualmente, sob responsabilidade do referido grupo. Essa é uma das ações para constituir a unidade do grupo por meio de associados e de outros membros que visitam o Festival e mergulham nas construções culturais ofertadas pelo Grupo Hikari por meio da dança.

A dança se apresenta intimamente conectada ao conceito de cultura, pois se constitui como sistemas de significados criados historicamente em termos dos quais os autores direcionam suas vidas, conforme explicitado na fala de C1: "O valor é cultural, é o resgate dela por meio da dança". Tal reflexão é posta por Lara (2013b), ao discutir os aspectos da cultura popular como as formas complexas de organização de vida de um dado grupo social, como mecanismo de luta e de criação de identidades que arrematam o mundo material ao simbólico e, por isso, apresentam as teias de significados daqueles que pertencem ao grupo e não estão alheias às transformações sociais que perpassam a vida desses grupos.

O valor cultural expresso na fala da coordenação retrata a manutenção das tradições do Japão que vê no Bom Odori uma possibilidade para fazê-la, uma vez que a dança 
representa a religiosidade desse grupo social: "o Bon Odori é uma manifestação cultural da Igreja Budista trazida para o Brasil pelos imigrantes. É realizada por motivo de festa, de alegria e de confraternização" (C1). Foi percebido que as manifestações da dança são vivenciadas e compreendidas pelas pessoas que as praticam dentro de uma dialética da vida cotidiana, na qual os signos se conectam entre si.

A dança se apresenta como forma de comunicação com o sagrado, celebração de atividades da vida cotidiana que são responsáveis por transformar a dança, o que atrela o processo de modernização da própria tradição, como observado na fala do coordenador: "ela mantém a tradição e vai modernizando" (C1). Laraia (2004) afirma que qualquer sistema cultural está num contínuo processo de mudança, ou seja, a conservação é sempre algo relativo, depende da dimensão de tempo e do sistema cultural a ser considerado. É certo, entretanto, que o fenômeno cultural também pode mostrar uma estabilidade considerável no decorrer do tempo e no espaço.

Nesse sentido, percebemos nessa temática que, ao mesmo tempo em que as tradições são mantidas, também são (re)significadas com as mudanças sociais ocorridas dado o caráter dinâmico da cultura na ordem moderna. Tal fato é evidenciado pela teoria de Canclini (1983), que entende a tradição como manifestação que busca, na modernidade, um meio para seu desenvolvimento por meio de processos que a transformem. Daí pensar, assim como fez Canclini (1983), que as tradições acompanham as mudanças ao longo do tempo e também podem se alterar, haja vista que se manifestam por ações humanas que, embora se constituem em gestos repetitivos, modificam-se ante às necessidades dos sujeitos históricos.

\section{Da dança no Grupo Sansey}

Dentre os grupos investigados, tem-se o Grupo Sansey, criado em 1988 por iniciativa de um grupo de jovens da Mity Karaokê Kyoshitsu ${ }^{9}$, escola de Karaokê da cidade de Londrina. Em 1994, o grupo foi constituído legalmente, com a denominação de Grupo Sansey - Cultural e Beneficente, cujo foco estava na preservação, valorização e divulgação da cultura japonesa na cidade de Londrina e em regiões metropolitanas da cidade. O reconhecimento do Grupo constrói-se pela obtenção de títulos relacionados às suas ações na cidade, a exemplo do Diploma de Reconhecimento Público, em 2010, pelas atividades realizadas a mais de 20 anos em prol de cultura japonesa e filantropia.

A relação do Grupo Sansey ${ }^{10}$ com a cultura japonesa estabelece-se diante de diferentes ações culturais, dentre elas: as festas, as danças e as músicas que trazem consigo

9 Atualmente, recebe o nome de Mity Escola de Karaokê.

10 A reportagem de junho de 2008, divulga a participação do Grupo Sansey no Festival de Yosakoi Soran no Japão realizado na cidade de Sapporo, província de Hokkaido. Foi a primeira vez que o Grupo Sansey se apresentou no Japão. A notícia revela que o Yosakoi Soran é uma dança que exige bastante dos dançarinos por ter movimentos fortes. "O Yosakoi Soran se tornou uma febre no arquipélago, principalmente entre os universitários, como acontece no Brasil com o forró, redescoberto e repaginado. É o resgate de duas danças folclóricas japonesas com um pouco de modernidade. Surgiu, em 1991, quando alguns jovens de Hokkaido, ilha ao norte do Japão, passavam feriado na província de kochi e conheceram o Yosakoi Matsuri" (LEMES, 02 abr. 2008. Folha 2) 
a transmissão dos artefatos culturais nipônicos. Em 2008, conforme notícia documentada no periódico investigado, o Grupo Sansey foi responsável por organizar a festa de comemoração do centenário da imigração japonesa no Brasil, na cidade de Londrina, na qual também houve a comemoração dos vinte anos de formação do Grupo.

A gestualidade do Grupo Sansey estrutura-se pela disseminação do Matsuri Dance, técnica corporal desenvolvida pelo próprio grupo, por meio da estilização de movimentos, instrumentos, e músicas que integram o cenário pop japonês contemporâneo. Essas transformações dão-se a partir de referências criadas pelo Bon Odori e pelos taikos - tambor milenar japonês, conforme explicitado pela entrevista do coordenador do Grupo: "o Matsuri Dance é a versão pop do Bon Odori, mistura de coreografia típica, canções folclóricas e ritmos ocidentais de apelo jovem" (C2).

A partir dessa percepção, é possível reconhecer a ideia de dinamicidade que também perfaz a tradição, uma vez que os atores sociais que a desenvolvem estão em constante mudança, pois, sofrem influências e influenciam o mundo a sua volta. Por isso, pensar num conceito de tradição implica, segundo Canclini (2004), na reflexão de algo que não se encontra bruto, mas em manifestações que possuem coerência num dado contexto social, uma vez que é nele que elas se dissipam e se proliferam, mas não deixam de sofrer processos de hibridação e conjugação com outras culturas e, também, com outros interesses.

Outra manifestação dançante ligada ao Grupo Sansey é o Yosakoi Soran, dança contemporânea japonesa que une tradição e modernidade e que se caracteriza pela alegria, pela energia, e pela força nos movimentos. De acordo com Lemes (2008), essa dança tornou-se presente no Japão, principalmente entre os universitários, pois retrata a hibridização entre as danças folclóricas japonesas e as danças da contemporaneidade. A relação entre o Grupo Sansey e a dança Yosakoi Soran aparece como elemento forte que une os imigrantes ao país de origem, fato ilustrado pela presença do Grupo Sansey, em julho de 2008, no Festival de Yosakoi Soran, realizado na cidade de Sapporo, província de Hokkaido, no Japão.

O diálogo com o coordenador do Grupo Sansey permitiu traçar olhares sobre os aspectos ligados à origem social do grupo e a manutenção da tradição japonesa por meio do envolvimento dos "jovens a conhecer suas tradições e transmitir a outras gerações e a outros povos" (C2). A consolidação do Grupo dava-se por meio de ações coletivas e pagamentos de mensalidades de novos integrantes, como explica o coordenador: "O grupo é cultural beneficente. Fazemos promoções para ajudar na manutenção dos instrumentos, do figurino. As turmas novas pagam uma mensalidade para manter o grupo, pagar a energia e outros gastos" (C2).

Ainda, outra contribuição decorre das festas organizadas pelo Grupo, como o Londrina Matsuri, a maior comemoração nipônica da cidade que ocorre na primavera, de maneira anual. Nesse festejo, a tradição do grupo mantém relação com os descendentes japoneses da cidade e de outras várias etnias, que acabam por visualizar os traços culturais presentes no bojo da cultura japonesa, o que auxilia na aceitação, assimilação e reprodução dos aspectos culturais do referido grupo. Por isso, na festa, há espaço para as 
apresentações artísticas que ocupam posição de destaque junto à organização do Grupo Sansey, a exemplo do Matsuri Dance e do Yosakoi Soran.

Dentre os sentidos e significados expressos pelas danças, a entrevista possibilitou a apreensão da dança como uma linguagem corporal, como meio de transmissão e comunicação, capaz de transmitir os sentimentos, emoções ligadas à tradição e às ideias. Como a dança é de origem japonesa, há o estreitamento entre a tradição e os símbolos sociais por ela estabelecidos, conforme relato do coordenador:

É uma dança que simboliza os pescadores, os gestos originais são movimentos de jogar e puxar a rede de volta. Nessa dança utilizamos um instrumento chamado Naruko, que parece um chocalho que os japoneses colocavam nas plantações de arroz para espantar os pássaros (C2).

Embora o elemento da tradição apareça na dança, também foi possível verificar a produção e elaboração das coreografias buscando interpretar o tradicional por meio da inserção de novas possibilidades de dançar a partir de vídeos disponibilizados na internet:

São os próprios integrantes que montam as coreografias. Pega inspiração de vídeos, mas tem uma equipe preparada para montar coreografias e vão montando de acordo com o tema da música do ano (C2).

Tem-se, com isso, a transmissão cultural da dança a partir de interferências culturais contemporâneas que mesclam sentidos e significados dos movimentos tradicionais - transmitidos pelos integrantes antigos - e dos movimentos estilizados - incorporados pelos jovens. Esse fato, pode ser dado em razão do Grupo Sansey participar ativamente de competições em nível regional, nacional e internacional, o que contribui para a assimilação de novas exigências ligadas à dança, como a inserção de novos instrumentos na música, de novos adereços e ornamentos e de novos movimentos - estilizados a partir da necessidade do grupo.

Tais transformações, segundo Lara (2013b), evidenciam a construção coletiva relacionada à dança que é seguida, respeitada e, quando necessário, é transgredida principalmente, quando os elementos outrora presentes, não atendem às necessidades do coletivo no presente. Ainda, a autora reflete sobre o campo cultural não como o embalsamento das tradições, mas a representação das mesclas entre o arcaico e o contemporâneo, em suas reações de conformismo e resistência, discussão realizada por Chauí (1995).

\section{Da dança no Grupo Ryukyu Koku Matsuri Daiko}

O grupo Ryukyu Koku Matsuri Daiko, cujo nome significa Tambores Festivos do Reino de Ryukyu, foi fundado em 1982, em Okinawa (Ilha ao Sul do Japão). Essa união tinha como objetivo revelar, preservar e difundir as riquezas das culturas e das tradições locais por meio do Eisá - manifestação artística que utiliza o som do taiko, o ritmo do 
sanshin ${ }^{11}$ e a dança. O grupo possui filiais em Okinawa, em outras províncias do Japão, em Los Angeles, no Hawaí, no Brasil, na Argentina, no Peru, na Bolívia e no México.

De acordo com a entrevista concedida, o Grupo surgiu em 2007, numa associação japonesa existente em Londrina, Associação de Okinawa (Província do Japão). Por meio dessa associação, houve encontro dos descendentes dessa província que moravam em Londrina, o que culminou na realização de reuniões e festas com o intuito de estimular a transmissão da tradição. Após esse momento, houve uma possibilidade de intercâmbio com o Japão, o que viabilizou novas formas de contato com a cultura nipônica, como é apresentado no relato de C3:

Partindo da necessidade de organizarem atividades para as crianças, fizemos cursos e estudamos vídeos sobre o estilo Eisá, que é uma dança misturada com Taiko, para ensinar as crianças. Em 2008, ano do centenário da imigração japonesa, foi realizado um projeto com o governo japonês no qual recebemos verba para transmissão dessa tradição aos descendentes. Adquirimos instrumentos, roupas típicas (C3).

O grupo tem como objetivo transmitir a tradição do estilo Eisá e Taiko para os jovens e para as crianças. São os próprios integrantes que administram o Grupo, tendo os adolescentes e os jovens a tarefa de ensinarem os mais novos, organizando as apresentações e os ensaios ao longo do ano, conforme explica o recorte abaixo:

O grupo abre turma uma vez por ano, a pessoa aprende a dança e treina o ano todo e, no final do ano ela recebe o uniforme para apresentar. Cobramos uma mensalidade para manter o grupo (C3).

Muito além da divulgação da cultura japonesa, os grupos produzem obras artísticas em suas manifestações dançantes. As danças são carregadas de códigos simbólicos expressos nos gestos dos dançarinos que mostram uma ligação do passado com o presente, do sagrado com o profano, da totalidade corpórea, numa obra em que a linguagem escrita é incapaz de expressar.

(...) temos por objetivo a divulgação da cultura. Apesar de ter o histórico ligado aos significados que vieram da Ilha, o que procuramos é divulgar um pouco dessa cultura específica da província de Okinawa que não pode nem considerar como uma cultura do Japão, pois é uma cultura específica de lá, que é considerada japonesa (C3).

Sobre a relação do grupo com a sociedade local, foi possível perceber que as relações com comemorações sociais e festas mostraram a organização da tradição do Londrina Matsuri, junto à Expo Japão, entre outros eventos. É perceptível a intensa conexão da cultura étnica japonesa com a cultura brasileira. Os grupos reconhecem as apresentações como espaços de fronteiras étnicas e culturais e, por isso, o espetáculo tem como objetivo atrair o público.

11 Taiko e sanshin são instrumentos musicais da província de Okinawa. 
Ainda, relataram que a sociedade local com sua diversidade étnica tem uma boa receptividade da cultura japonesa, o que oportuniza várias apresentações em escolas, eventos, feiras, exposições locais, regionais e em outros estados onde as filiais se reúnem. As danças e festas promovidas pelos grupos japoneses tem o papel social de estabelecer ligações com suas origens étnicas e, ao mesmo tempo, dialogar com a sociedade londrinense os diferentes signos presentes na cultura japonesa e suas possíveis ressignificações ao confrontar-se com outras culturas.

Ao refletir sobre os aspectos que interligam tais campos culturais, é necessário pensar a cultura como campo de disputas, assim como faz Hall (2003). Para esse autor, a cultura é um espaço de luta, o que quer dizer que qualquer transmissão cultural é sempre travada, disputada, conquistada e transformada pelos grupos envolvidos. Insere-se como uma construção que ocorre nas relações entre os diversos grupos sociais e entre seus membros que não ocorre de maneira passiva, a partir de agente que meramente reproduzem gestos e valores de maneira arbitrária.

Por meio da análise dos dados foi possível inferir que o grupo (re)significa a dança, construindo movimentos híbridos que são incorporados à dança, uma vez que, embora sua raiz esteja centrada em Okinawa, no Japão, os gestos se reconstroem e seguem as mudanças sociais. Tais transformações edificam-se em meio a momentos de celebração ou de registro de atividades cotidianas e de acontecimentos sociais, como comunicação com o sagrado. Daí ser possível perceber que os aspectos mesclam a tradição ao contemporâneo, evidenciando a invenção dos indivíduos que integram tal manifestação. Como observa, Certeau (1998) essas "artes de fazer" remetem às maneiras pelas quais as manifestações culturais contemporâneas são apropriadas na sociedade contemporânea, consolidando formas de resistência que alteram códigos culturais.

\section{CONSIDERAÇÕES FINAIS}

O interesse central do artigo esteve respaldado pela investigação das manifestações da dança japonesa em Londrina, por meio da apreensão dessa cultura corporal via diálogo com diferentes grupos que se organizam com o intuito de assimilar, transmitir e, quando necessário, transgredir a tradição quando novas demandas surgem nos diferentes contextos em que se inserem.

Os artefatos culturais da dança foram representados por um sentimento de pertença à nação japonesa e orgulho dos valores dos antepassados e a necessidade de conquista das novas gerações. Por isso, a dança japonesa na cidade de Londrina, estrutura-se no sentido de contribuir para a permanência da cultura dos japoneses imigrantes e suas famílias e, também, para construir uma cultura própria da colônia que se estabeleceu na cidade, adaptada a partir das novas demandas culturais remanescentes da sociedade contemporânea.

Os hábitos ou os modos de vivenciar a tradição japonesa sofreram adaptações no Brasil, pois não há como reproduzir, exatamente, o que ocorre num país - demarcado pela sua língua, vestimenta, alimentação, entre outras peculiaridades culturais - em um país 
diferente, no caso, o Brasil. Por conseguinte, a tradição cultural japonesa passou por um filtro brasileiro e vive outra realidade. Não é exatamente uma copia ou mera reprodução, ao contrário, é uma maneira de conservar a tradição, adequando-se ao contexto brasileiro.

As danças apresentadas pelos grupos se inserem no sistema particular de arte e, consequentemente, no sistema geral de formas simbólicas que constitui a cultura. Geertz (1997) explica que isso ocorre em razão de que a arte é um setor da cultura. Por conseguinte, as manifestações da dança japonesa mostraram a existência de (re)significações dos signos sociais na própria sociedade brasileira e não em um mundo fictício de dualidades.

Por fim, a inferência dos dados permitiu identificar os significados atribuídos às manifestações dançantes japonesas e suas ressignificações manifestadas pelos brasileiros descendentes de japoneses que buscam a preservação de suas tradições. Esses dados possibilitaram a compreensão atribuída às gestualidades dançantes desse grupo étnico e, assim, a viabilização de processos de alteridade no trato com o conhecimento da dança.

\section{REFERÊNCIAS}

ALVIM, Zuleika. A Vida Privada dos Pobres do Campo. In: NOVAIS, Fernando; SEVCENKO, Nicolau. (Orgs.). História da Vida Privada no Brasil. São Paulo: Companhia das Letras, V.2, 1998.

ARIAS NETO, José Miguel. O Eldorado: representações da política em Londrina (19301975). 2 ed. Londrina: Ed. UEL, 1998.

ASARI, Alice Yatiyo. E eu só queria voltar ao Japão: colonos japoneses em Assaí (PR). 1992. Tese (Doutorado) Faculdade de Filosofia, Letras e Ciências Humanas da Universidade de São Paulo, São Paulo, 1992.

BARDIN, Laurence. Análise de conteúdo. São Paulo: Edições 70, 2011.

BOURCIER, Paul. A história da dança no ocidente. 2 ed. São Paulo: Martins Pontes, 2001.

CAMARGO, Fernanda Marques Tresinari; SBORQUIA, Silvia Pavesi. Mapeamento dos grupos de dança em Londrina-Pr. In: Encontro anual de iniciação científica e encontro anual de iniciação tecnológica e inovação, 2013, 22, 3, Foz do Iguaçu. Anais... Foz do Iguaçu, 2013.

CANCLINI, Nestor Garcia. As culturas populares no capitalismo. São Paulo: Brasiliense, 1983.

. Culturas híbridas: estratégias para entrar e sair da modernidade. 4 ed. São Paulo: Edusp, 2004.

CAPELO, Maria Regina Clivati. Educação, escola e diversidade cultural no meio de Londrina: quando o presente reconta o passado. 2000. Tese (Doutorado em Educação) Universidade Estadual de Campinas, Campinas, 2000.

CERTEAU, Michel de. A invenção do cotidiano: artes de fazer. 3. ed. Petrópolis, RJ: Vozes, 1998.

CHAUÍ, Marilena. Conformismo e resistência: aspectos da cultura popular no Brasil. São Paulo: Brasiliense, 1995. 
FARO, Antonio José. Pequena história da dança. 4 ed. Rio de Janeiro: Zahar, 1998. FERNANDES, Priscila Martins. Identidade e memória de imigrantes japoneses e descendentes em Londrina 1930-1970. Dissertação (Mestrado) Universidade Estadual de Londrina, Londrina, 2010.

GEERTZ, Clifford. A interpretação das culturas. Rio de Janeiro: Guanabara Koogan, 1989. . O Saber local: novos ensaios em antropologia interpretativa. Petrópolis, RJ: Vozes, 1997.

HALL, Stuart. Da diáspora. Identidades e mediações culturais. Belo Horizonte: UFMG Brasília: Representação da UNESCO no Brasil, 2003.

KUBOTA, Nádia Fujiko Luna. Bon Odori e Sobá: As Obasan na Transmissão das Tradições Japonesas em Campo Grande-MT. Dissertação (Pós-Graduação em Ciências Sociais) Universidade Estadual Paulista, Marília, 2008.

LARA, Larissa Michelle. Dimensão epistemológica da dança: leituras, prospecções incompletudes. In: LARA, Larissa M. (Org.). Dança: dilemas e desafios na contemporaneidade. 1ed. Maringá: Eduem, 2013a.

. Maracatu-nação e sentido ético-estético do corpo. In: Isabel Cristina Martins Guillen.

(Org.). Inventário cultural dos maracatus nação. 1ed. Recife: UFPE, $2013 \mathrm{~b}$.

LARAIA, Roque de Barros. Cultura: um conceito antropológico. 17 ed. Rio de Janeiro: Jorge Zahar, 2004.

LEMES, Francismar. Londrinenses dançam na Terra do Sol Nascente. Folha de Londrina, Londrina, 02 abr. 2008. Folha 2, p.1.

MAESIMA, Cacilda. Japoneses, multietinicidade e conflito na fronteira: Londrina, 1930/1958. Tese (Doutorado), Departamento de História, Instituto de Ciências Humanas e Filosofia, Universidade Federal Fluminense, 2012.

MAUSS, Marcel. Sociologia e Antropologia. São Paulo, EPU/EDUSP, 1974.

NEIRA, Marcos Garcia; NUNES, Mario Luiz Ferrari. Pedagogia da cultura corporal: crítica e alternativas. São Paulo: Phorte, 2006.

OGAMA, Walter. Bom Odori para entreter os vivos. Folha de Londrina, Londrina, 07 jun. 2002. Folha 2.

OGUIDO, Homero. De imigrantes a pioneiros: a saga dos japoneses no Paraná. Curitiba: [s.n.]. 1988.

PORTINARI, Maribel. História da dança. Rio de Janeiro: Nova Fronteira, 1989.

SÁNCHEZ GAMBOA, Silvio. A pesquisa na construção da universidade: o compromisso com a aldeia num mundo globalizado. In: José Claudinei Lombardi. (Org.). Pesquisa em Educação, História, Filosofia e Temas Transversais. 2 ed. Campinas: Autores Associados, 2000.

SANO, Rui Kban. Japoneses: sonhos e pesadelos. Trabalhadores, Campinas, SP, p.1-4, 1989. Disponível em: <www.terrabrasileira.net/folclore/influenc/japonhis.html>. Acesso em: 7 mar. 2008.

SANTOS, Boaventura de Sousa. Um discurso sobre as ciências. São Paulo: Cortez, 2003. SBORQUIA, Silvia Pavesi; NEIRA, Marcos Garcia. As danças folclóricas e populares no currículo da Educação Física: possibilidades e desafios. Motrivivência, ano XX, $\mathrm{n}^{\circ} 31$, p. 7-98, dez/2008. 
SCHWARTZ, Widson; FUZII, Estela Okabayashi. (Orgs.). História da imigração japonesa no Paraná. Londrina (PR): Aliança Cultural Brasil-Japão do Paraná, 2005.

SILVA, Tomaz Tadeus da. A produção social da identidade e da diferença. In: SILVA, Tomaz Tadeu da. (Org.) Identidade e diferença: perspectiva dos Estudos Culturais. Petrópolis: Vozes, 2000.

TRIVIÑOS, Augusto Nibaldo Silva. Introdução à pesquisa em ciências sociais: a pesquisa qualitativa em educação. São Paulo: Atlas, 1997.

WAWZYNIAK, Sidinalva Maria dos Santos. "Colônia" como representação: Imigração japonesa no Brasil. In: HASHIMOTO, Francisco; TANNO, Janete Leiko; OKAMOTO, Monica Setuyo. (Orgs.). Cem anos da imigração japonesa: história, memória e arte. São Paulo: Editora da UNESP, 2008.

YAMAKI, Humberto Tetsuya. Mini atlas da colônia internacional: as terras da CNTP. Londrina: Edições Humanidades, 2008.

Recebido em: Julho/2017 Aprovado em: Novembro/2017 